\title{
Joyería púnica en Melilla: Los pendientes de la necrópolis del Cerro de San Lorenzo
}

\author{
Paloma Moratinos Bernardi
}

\section{Introducción general}

La orfebreria se refiere fundamentalmente al trabajo sobre metales preciosos, si bien, pudiera aplicarse únicamente al oro ya que otros metales como la plata tiene para sus labores una designación más especffica.

Incluye, en general, piezas muy diversas, desde las muy pequenas a las de gran formato, entre las primeras se pueden incluir buen número de muestras civiles joyas u objetos de adomo, joyas de uso religioso, etc.

Las técnicas de trabajo han sido muy diversas a lo largo de la historia y han recibido diferente valoración en cada momento. A menudo se han reunido en una misma pieza con el deseo de lograr su mejor omamentación; entre las modalidades más destacadas están las siguientes que se encuadran en dos grandes grupos:

1.) Decoración basada en el exclusivo trabajo de la plancha de metal.

2.) Omamentación complementaria que consiste en añadir motivos del mismo metal en otro distinto o en materiales diferentes, todos ellos trabajados de formas diversas.

En el primer grupo la labor técnicamente más simple es la del "Grabado" basado en la incisión ligera de una superficie, ya sea en hueco o en relieve mediante el uso del instrumento punzante adecuado. Esta modalidad también se le conoce por el nombre de "Burilado" o "Grabado a Buril" ya que éste suele ser el instrumento adecuado.

Otra técnica es la del "Repujado" que parte como el "grabado" y el "cincelado" de esa modalidad común a muchos metales que es la maleabilidad que hace que se puedan batir y extender en láminas o planchas. De este modo su superficie lisa puede ser modificada, dándole un relieve que en el caso del "repujado" se realizara martilleando por el reverso hasta conseguirlo en saliente por el anverso.

Como variante del repujado se seffala una técnica llamada "De haz y envés" usada en el mundo antiguo, se basa en la utilización de dos láminas o planchas de metal, en la primera, exterior, se "repujaba" el motivo y una vez hecho, se soldaba a una segunda lámina lisa que quedaba por el interior, adaptándose 
ambas a la forma de la pieza; finalmente el hueco existente entre las dos planchas se rellenaba con una resina, de modo que su interior fuera consistente y no se abollara con los golpes.

Asimismo el grabado y el repujado se pueden hacer directamente sobre la plancha creando un relieve a partir de un dibujo previo, o bien lograr el motivo por "estampación" golpeando el metal sobre una matriz o molde que reproduzca en relieve o hueco el modelo elegido.

La técnica del "cincelado" emplea también el martillo como instrumento principal y por medio de golpes suaves sobre el cincel consigue hacer los planos y aristas del modelado. Es una labor que se realiza al contrario que la anterior, por el anverso, usándose a menudo para repasar y retocar otras técnicas como el repujado o las piezas hechas por fundición.

Dentro de las formas básicas de creación de una pieza se puede incluir también la "fundición artística" empleada esencialmente para hacer pequeñas figuras de oro aisladas. Su técnica se conoce por "fundición a la cera perdida" y abarca dos procedimientos de trabajo. En ambos se comienza haciendo un modelo en cera de la figura que se recubre después de una capa de barro, yeso u otra sustancia refractaria que se adapte perfectamente al molde en cera. Seca ésta se realizan dos aberturas, arriba y abajo de la pieza, y se vierte por la superior el metal fundido en colada de modo que al entrar en el interior derrita la cera con su calor, que como consecuencia sale por el orificio inferior quedando en su lugar el metal; una vez enfriado, se rompe el molde, obteniéndose una figura maciza.

La otra técnica es la de "cera perdida con alma interior" que sirve para grandes piezas, con lo que se abarata la pieza. La fundición del metal puede igualmente hacerse por partes con moldes, por ejemplo con molde univalvo, en dos partes uniendo al final todos por soldadura, esto ocurre en las piezas grandes.

Otras fórmulas más simples de trabajo son el "perforado o recorte" de una lámina de metal dándole una determinada forma plana que puede dejarse aislada o superponerse.

En el segundo grupo, el de ornamentación complementaria, se incluyen otros métodos que permiten añadir motivos superpuestos a una pieza hecha en un material concreto, entre ellos además del "Recorte" tenemos el "Damasquinado" y el "Nielado";

Una técnica más compleja es la de la "Filigrana" que se basa en una adición de hilos y gránulos metálicos que formando dibujos muy diversos se van soldando a la pieza metálica. Este trabajo resuita sobrepuesto y en relieve y puede presentar variaciones más o menos complicadas según que el hilo sea de mayor o menor grosor, esté o no retorcido, etc.

Dentro de esta misma técnica existe otra variedad llamada "Granulado" labor que consiste simplemente en la soldadura de pequefias bolitas de oro.

Por último habria que añadir la adición en una pieza de piedras y esmaltes. 
La orfebrería surge como una de las manifestaciones artísticas más antiguas, en épocas en que el hombre todavía nómada no se había asentado hasta el punto de crear una arquitectura estabilizada. Aparece desde sus inicios como una forma artística que más que funcional (que lo es) es ornamental y, sobre todo, se presenta como una imagen distintiva de clase ya que a merced del valor fluctuante de los metales se vincula a la élite dominante.

Prestigio, poder y formula de omamentación son, pues, tres de los calificativos que definen a la orfebrería desde sus comienzos, y se aplican sobre todo al apartado de la "Joyeria".

Las joyas que son objeto de este estudio son unos pendientes de lámina de oro en forma de pájaro posado (paloma) que se encontraron en un enterramiento de la necrópolis púnica que existra en el desaparecido Cerro de San Lorenzo de Melilla; la cronologia que siempre se les ha dado es algo imprecisa, va del siglo III al siglo I a. C., es decir de la última etapa de la cultura púnica según algunos autores, otros adelantan esta fecha.

Por lo tanto empezare dando una visión general de la joyerfa y el adomo femenino en el mundo púnico.

\section{La joyería en el mundo púnico}

El propio concepto de adorno es muy complejo, pero aparte de un simple deseo de placer, es preciso ver en él una significación mágica que se expresa en el deseo de aparentar, de mostrar cierta pujanza, cierto poder, en una palabra cierta riqueza.

Desde la más remota antiguedad la mujer ha sabido por diversos procesos, revalorizar su cuerpo, asociado siempre a la fecundación, concebido como un verdadero ejemplo, como un tabernáculo sagrado que abriga la vida. En el caso de las joyas, aparte de su significación mágico-religiosa ha seguido constituyendo para las mujeres un patrimonio casi inalienable.

Una producción muy característica del artesanado púnico son las joyas, pues hay que tener en cuenta que parte de su comercio se basa en recoger materias primas: oro, plata, estaño en bruto... en los lugares donde se hallaban y transformarlas en joyas y venderlas quizás a los mismos que les habran suministrado la materia prima.

Las necropolis púnicas han proporcionado una cantidad formidable de joyas de todas clases: collares, sortijas, pendientes, brazaletes, anillos para las orejas y la nariz, fíbulas... cuya materia, el oro fundamentalmente, o el electrón combinado con elementos más simples como la plata vitrea o las piedras preciosas o semipreciosas como la coralina, el granate, el lapislázuli, etc. daban una vistosa realización, unas formas delicadamente trabajadas, una gran diversidad y número testimonian la existencia de hábiles artistas y refinados consumidores.

Estas piezas, encontradas fundamentalmente en las tumbas y cuyo papel religioso si no mágico es evidente, nos dejan imaginar el esplendor de todas 
aquellas otras que llevarian realmente los ricos cartagineses.

El trabajo típicamente púnico es la técnica de la "filigrana" y de la "granulación o granulado", la decoración ejecutada en filigrana es de una técnica y un arte consumados, el más frecuente de los motivos es el geométrico: triángulos punteados y líneas onduladas o trenzadas. Cuando la filigrana se forma con bolas minúsculas, acoladas en caliente una a una se le denomina granulado, esta modalidad en principio importada se transformó en manos de los orfebres púnicos en un arte de gran calidad. A veces se simplifico el procedimiento entretallando un hilo de oro para darle aspecto de filigrana, esta técnica tiene mucha menos finura pero era más rápida, todavía en uso en las joyas orientales actuales.

La ostentación de pendientes es típico del arte púnico y fueron como en el mundo ibérico, usados indistintamente por ambos sexos, aunque los que se hacen en barro sólo lo utilizaban las mujeres. Los hay de muchos tipos: simples colgantes bicónicos, rodetes (de varios tipos), de roseta, de racimo, de serpiente enrollada, de pájaro, de cabeza humana, etc.

\section{Melilla y la necrópolis púnica del Cerro de San Lorenzo}

El profesor Tarradell en una de sus ponencias del "I Congreso Arqueológico del Marruecos Español", que se celebró en Tetuán entre el 22 y el 26 de junio de 1953 hablo de las excelentes condiciones que presentaba Melilla desde el punto de vista de las navegaciones antiguas; para él, era evidente que no tenían que ser desaprovechadas por los navegantes cartagineses en su ruta a lo largo de las costas norteafricanas, camino del Estrecho de Gibraltar.

Uno de estos establecimientos fue Rusadir, sobre la pequeña península rocosa, de aproximadamente 30 metros de altura en la que todavía se asienta la Ciudad Vieja de Melilla. Las más antiguas referencias históricas del Mediterráneo Occidental han permitido identificar a la actual ciudad de Melilla con la antigua Rusadir fenicia. Para el P. Fita el nombre de Rusadir está formado por la yuxtaposición de dos vocablos púnicos: "Rus" que significa cabo o promontorio y "Addir" grande o eminente, alusión (parece ser) al Cabo de Tres Forcas en cuya parte oriental se asienta Melilla.

Consta que durante la dominación cartaginesa Rusadir importante lugar de comercio por su enclave geografico, acuńo moneda propia destinada a sus transacciones mercantiles. Varios escritores antiguos nos han dado su nombre: Plinio cita Rusadir Oppidum et Portus, el Itinerario de Antonio nos da Rusadder Colonia y también Ptolomeo la cita. A través de su nombre, sin duda púnico, como deća el P. Fita, se ha supuesto siempre que fue una fundación cartaginesa La situación no puede ser mas atractiva al pié del gran saliente del Cabo Tres Forcas una pequefia península rocosa se adelanta en dirección E. Por el lado de Levante está separada de la tierra por un istmo de escasa anchura, presenta, por tanto, magnificas condiciones defensivas.

Al Sur de esta Península se abrfa una pequeffa playa en dirección al SW. que 
se inclinaba suavemente hacia mediodía para ir a parar, cambiando ligeramente de dirección, a la Mar Chica. A poca distancia hacia el S. de la actual Melilla la Vieja, el riachuelo llamado Río de oro y algo más al S. es decir, en la parte opuesta al río del promontorio rocoso se elevaba una redondeada colina, el Cerro de San Lorenzo.

Las invasiones y guerras que siguieron a la carda del Imperio Romano hicieron desaparecer de la superficie las huellas de sus antiguos pobladores: visigodos, bizantinos y árabes reedificaron y destruyeron sucesivamente la ciudad. En el siglo XV sus habitantes, por las contínuas rivalidades entre los reyes de Fez y Tlemecén despoblaron la ciudad y se fueron a vivir a otros pueblos aunque previamente la asolaron. $Y$ es en este momento histórico en el que aparecen los españoles que mandados por Pedro de Estopiñan y Virúes ocupan Melilla, deshabitada y en ruinas, en la noche del 17 de septiembre de 1497.

A principios de este siglo empezaron los descubrimientos arqueologicos en el subsuelo inmediato a la roca, que sustenta el núcleo antiguo de Melilla, los hallazgos fueron obra del azar, coincidiendo con la construcción de zanjas o cimientos de nuevos edificios. El más rico yacimiento, el único excavado y no totalmente se encontró en el Cerro de San Lorenzo, desaparecido en 1940 por necesidades urbanisticas, aunque hay que sefialar que en otros puntos de la ciudad se encontraron interesantes hallazgos.

Los descubrimientos arqueologicos del Cerro de San Lorenzo vinieron en cierto modo a corroborar el origen de la ciudad. Este cerro era una colina situada a 600 metros del recinto fortificado, al S-SW del Torreón de los Hombres del Campo.

De forma ovoide, esta colina estaba orientada al NE-SE, su lado oriental terminaba en suave declive en la playa y tenía una elevación de 26,34 metros sobre el nivel del mar, (la vieja fortaleza del peñasco calcáreo, la antigua Rusadir se encontraba sólo a 4 metros más).

En 1883 los desterrados que cumplían condena en el penal de la ciudad abrieron los cimientos para construir el Fuerte de San Lorenzo y tuvieron que tropezarse con sepulturas de las necropolis alli existentes, pero desgraciadamente no queda consignación alguna del posible descubrimiento. Probablemente estos fueron los primeros hallazgos efectuados en el lugar, en la época moderna, según Tarradell.

En 1904 cuando se realizaban excavaciones para construir en la parte septentrional del Cerro el Matadero Municipal aparecieron tres esqueletos incompletos y dos ánforas de barro de gran tamaño, estos hallazgos fueron estudiados por el arqueólogo Juan Cabre quien les dió una cronologia del último período de la cultura púnica y albores del periodo romano, aproximadamente entre los siglos III y I a. C. El Profesor Tarradell piensa que no hay ninguna pieza de las que se encontro en la necrópolis que se pueda datar con seguridad en el siglo 
III a. C., en cambio hay bastantes ejemplares que tienen paralelos fechados, en el siglo II a. C. aunque es una datación aproximada, a su juicio, para el siglo I a. C. no hay dudas. El cree que hubo una primera época de factorfa de navegantes púnicos (de la que no queda nada) y una segunda que abarca principalmente los dos últimos siglos de nuestra era en la que debio existir una ciudad sucesora de la anterior, con aportaciones étnicas indígenas, los materiales conservados cree Tarradell que reflejan este momento y por ello piensa que deben ser denominados púnico-mauritanos.

Años después, en 1908, al abrir unas zanjas de cimentación en la parte oriental del Cerro para construir el Almacén de Cereales, la llamada Casa de los Silos, se descubrieron numerosos fragmentos de cerámica y dos ánforas completas de idéntica factura que las que aparecieron anteriormente.

Movido por la curiosidad de estos hallazgos el que fue primer cronista oficial de la Ciudad, Rafael Fernández de Castro, inició una pequeña exploración en las inmediaciones del Fuerte de S. Lorenzo y encontró otra ánfora incompleta y dos lacrimatorios. El alcalde de Melilla al conocer estos hallazgos puso a disposición de Fernández. de Castro una brigada de obreros con la que organizó la exploración del Cerro. Se comenzó con el trazado de zanjas o ramales en todas direcciones y pronto se encontraron numerosas sepulturas con restos humanos y un variado ajuar funerario.

A raiz de estos descubrimientos, en el Cerro tras las grandes lluvias, se producfan los arrastres y cambiaba en la superficie las tonalidades de las tierras; se descubrió a ras del suelo el contomo longitudinal de un ánfora de barro de gran tamaño con boca de trompeta, cuyos perfiles en fuerte color rojo destacaban sobre la coloración parda del terreno. Se practicó una ligera excavación para contomear el ánfora, logrando extraer la mitad inferior que alli quedaba, por debajo de ella apareció un lecho de arena muy fina con fragmentos de cerámica pertenecientes a dos anforitas o lacrimatorios.

Al poco tiempo Fernández de Castro llegó a la conclusión de que mientras en la parte más alta del Cerro aparecian sepulturas a pocos centímetros de la corteza del suelo, por la parte oriental se hallaban, en cambio, a una profundidad media de tres metros y la explicación serfa que en la Península de Tres Forcas los vientos dominantes son los del cuarto cuadrante (Poniente) y así mientras la progresiva acción de los elementos atmosféricos descarnaba los cerros de sus declives occidentales, los iba cubriendo, en cambio, de tierra vegetal y arenas por su parte oriental defendida del embate de estos vientos.

Sobre las antiguas sepulturas púnicas existían unos enterramientos con esqueletos de crecida talla, en la parte más elevada a oriente del Cerro, eran los restos de la guardia del Emperador de Marruecos Mulay Mohammed Ben Abdalah que puso sitio a la ciudad entre 1774-1775, en el sitio más descarnado de la colina los enterramientos musulmanes estaban orientados de Oeste a Este mientras los enterramientos púnicos tenian sus fosas orientadas en dirección Norte-Sur, con la cara vuelta hacia el Este. 
En opinión de Rafael Fernández de Castro el Cerro tuvo tres necrópolis en el transcurso del tiempo: una, púnica en el Nordeste en el declive que daba al mar, sobre esta misma se hallaban los enterramientos musulmanes del sitio puesto a Melilla en 1774-1775 y en la parte Noroeste del Cerro una necrópolis propiamente romana donde aparecían unas sepulturas bordeadas de tejas.

Los enterramientos púnicos tenían una pronunciada decoloración rosácea del terreno en la parte cental de la sepultura, al parecer por haber echado tierra procedente de otro lugar, quizás de veneración por parte de los naturales como si la ceremonia de echar en la sepultura esa clase de tierra arcillosa formara parte del ritual fúnebre en este tipo de enterramientos

A profundidades que en la altiplanicie y parte oriental del Cerro de San Lorenzo oscilaban entre los 1,30 y 3,00 metros, en terreno duro -conglomerado de areniscas - se hallaron ciertos enterramientos especiales cubiertos de ánforas de barro de boca de trompeta, de 1,05 a 1,10 metros de altura, con diámetro exterior de 23 a 25 centímetros. Estas ánforas se colocaban en sentido horizontal - a modo de losas - sobre los bordes de las propias fosas sepulcrales y su número siempre era impar, guardando relación con la longitud del cadáver depositado en la sepultura, las tumbas menores estaban cubiertas por tres ánforas y nueve tenía la mayor de las tumbas encontradas. Se colocaban alternadas las bocas de las ánforas que estaban rellenas de arena muy fina de río y caracoles Hélix.

La forma de enterramiento seguida en esta necrópolis consistra en depositar el cadáver dentro de una fosa abierta a gran profundidad, cuya caja de fondo, excavada en areniscas terciarias muy compactas, fue en algunas de ellas explanada con piedra caliza muy basta sobre la colocación de restos mortales, habiéndose encontrado junto a los maxilares del esqueleto y casi en contacto con los dientes, como en actitud de poder beber, una pequeña jarra de barro cocido con asa, un candil o lucerna de variados tipos, colocada próxima a las vértebras cervicales y a lo largo de la fosa, diseminados sobre el esqueleto, unas diminutas ánforas, ungüentarios o lacrimatorios que debran trocear antes de depositarlas, por haberse encontrado sus restos distanciados unos de otros. En la parte correspondiente a los piés, presentaban algunos de estos enterramientos tazas o páteras de barro en perfecto estado de conservación.

Debłan rodear el cadáver con arena muy cernida del próximo río, hasta dejarle cubierto a ras de los bordes del cajetín sepulcral abierto en el terreno, hendimiento al que ordinariamente daban unos 60 centímetros de anchura por otros tantos de fondo, nivelada la arena, pasaban a colocar encima las ánforas de cuello de trompeta, con que cubrian la fosa. Y sobre ellas hacían de nuevo relleno con tierra vegetal, como de metro y medio de espesor, vertiendo en su parte central, próximo al enrase de la fosa, la tierra arcillosa de color rosáceo que cité anteriormente.

Segun Tarradell este tipo de enterramiento no aparece ni en la necrópolis de 
Cartago ni en ninguna conocida en Africa del Norte enlazadas con la expansión púnica, la necropolis de Tamuda (Tetuán) la ciudad más próxima explorada de esta época y en la que se da abundante material emparentable con Melilla no tenía ni un sólo enterramiento similar, igualmente es desconocido el sistema en el ámbito romano, por lo que queda claro a través de sus materiales que se trata de un yacimiento prácticamente nada romanizado, como es 16gico, dado el país y la época. Tan sólo hay un caso con el que se pueda emparentar, a pesar de ser distinto, se trata de la necropolis púnica de Olbia en el NE. de Cercenfa, donde aparecen tumbas en cámara cuya puerta está cubierta no con una losa, como es normal, o con piedras amontonadas, sino con ánforas superpuestas, en posición alargada y una encima de otra. Estas tumbas están fechadas por Doro Levi en el siglo III a. C., la relación con un yacimiento púnico-sardo nos sitúa dentro del mismo ambiente que debio dar origen al núcleo de Melilla.

En una de las sepulturas punicas, que indudablemente debía pertenecer a una mujer, se hallaron además de la jarrita y el candil 6 lucerna, a uno y otro lado del cráneo los pendientes objeto de nuestro estudio, unos aretes de oro para el cabello y varias cuentas de ágata pertenecientes seguramente a un collar, también se encontraron dos lacrimatorios, dos ungüentarios y fragmentos de un alabastron troceado. Asimismo se encontro un pequefio trozo de hueso frontal con parte del arco superciliar derecho y otros diminutos fragmentos óseos. Varios autores estudiaron estos restos y los resultados fueron publicados en las Actas y Memorandums de la Sociedad Espanola de Antropologia, Etnología y Prehistoria IX (1930). Este es el único enterramiento del que conocemos exactamente su ajuar, ya que Fernández de Castro nos lo describe minuciosamente; los restos encontrados en las otras tumbas fueron mezclados cuando se llevaron al Museo Municipal por lo cual fue muy diffcil la clasificacion de los objetos encontrados en la necropolis de San Lorenzo.

En 1916 se suspendieron las excavaciones del Cerro, que no se volvieron a reanudar hasta épocas muy recientes. Mas aun, en 1940 la Corporación Municipal saco a subasta para mitigar el paro obrero la demolición del Cerro, ampliando asi los terrenos edificables de la nueva ciudad y los contratistas atentos a su negocio, para la más rápida saca de tierras utilizaron explosivos con lo que se debieron destruir muchas sepulturas, todavía inexploradas, que se perdieron definitivamente.

\section{Simbología de los pendientes}

Ya dije al principio que los pendientes representaban un pájaro en actitud de reposo, posiblemente una paloma; desde el tercer milenio en el Próximo Oriente, en el mundo egeo y especialmente en el pars fenicio y luego en el mundo cartaginés, la paloma está asociada a las divinidades de la fecundidad, se le consideraba como el ave más amoroso y prolifica y a la vez era como un símbolo de pureza y amor. 
En Chipre es donde el papel de este ave aparece más claro desde la época prehistórica a juzgar por los vasos con representaciones de palomas, en Siria tuvo un papel preeminente y estuvo asociada a la diosa Atargatis, en Fenicia era el animal sagrado de Astarte, diosa local de Aphca, en el mundo cartaginés está asociada con Tanit y se encuentra representada en numerosas estelas dedicadas a esta divinidad, en muchas terracotas ostentándola como atributo o como en este caso en unos pendientes de mujer.

En general, la paloma participa del simbolismo de todo animal alado (espiritualidad y poder de sublimación). Desde el Antiguo Egipto las aves simbolizan las almas humanas, conciemen al elemento aire y en consecuencia espiritualidad, la paloma es un ave que representa la sencillez, simboliza el candor y la humildad.

Pudiera ser que la mujer que tenía en su tumba como ajuar funerario estos pendientes fuera una sacerdotisa de la diosa Tanit, la Diosa Madre y Diosa de la Fecundidad, desde luego debra tener un papel relevante en la sociedad de esta colonia púnica del siglo II a. C., pues no se encontró ningún ajuar parecido, ni tan rico. A través de los diferentes símbolos materializados en la decoración de joyas, se expresan los atributos de esta diosa Tanit cartaginesa, de vieja rafz oriental, que debe ser considerada como una Gran Diosa o Diosa Madre en general, con todas las funciones y poderes de este tipo de divinidades femeninas prescritas en el mundo oriental desde los inicios de la agricultura y que por tanto repiten en sus símbolos los mismos caracteres que los de las deidades semejantes en las distintas religiones, a saber:

-Diosas celestes de los astros y muy especialmente de la Luna por oposición al Sol (símbolo masculino) y reconocidas como soberanas o reinas y por tanto adoradas como tales.

-Diosas de la tierra y por tanto de la vegetación, de los animales y de la fecundidad $o$ de la Vida en general.

-Diosas del mundo subterráneo, divinidades salvificas en relación con la Muerte.

A partir de este carácter de Gran Diosa su poder, determinado en cada sistema religioso lleva a representar entre sus símbolos sus acciones míticas que sirven de ejemplo o modelo para atraer la devoción de sus fieles por cuya mediación alcanza los favores esperados en la vida o en la muerte.

\section{Técnicas y Material}

Esta joya de adomo femenino compuesta por dos pendientes realizados con técnica de "Repujado", creo más bien que están hechos con una variante del repujado muy utilizada en el mundo antiguo, la técnica de "haz y envés". Esta técnica como dije al principio consiste en utilizar dos láminas o planchas, en este caso de oro, y en la primera o exterior (en este caso serian las dos exteriores, formando el cuerpo de la paloma) se repujaba el motivo deseado y una vez 
hecho se soldaba a una segunda lámina lisa, (en este caso no serfa lisa sino también repujada) adaptándose ambas a la matriz o modelo (la paloma), que mediante estampación, es decir golpeando las láminas de oro sobre el molde, se había conseguido. Cuando se han soldado ambas láminas, siempre dejando un pequeño agujero, (en este caso en la parte trasera, donde luego anadirfa la pieza de la cola) por él se vertía una especie de resina que se acoplaba perfectamente al hueco existente entre las dos láminas, daba consistencia al interior y lograba que no se abollara la pieza con los golpes.

Esta hipótesis sobre la técnica utilizada la baso en unas declaraciones del joyero melillense que hace pocos años realizo unas copias de estos pendientes; según él cuando manejaba uno de los pendientes al estar en contacto con el calor desprendió una sustancia pegajosa que él dijo desconocer y que se encontraba en el interior del pendiente. Siempre se ha crefdo que estos pendientes estaban huecos, con lo cual serfa posible que se hubiera utilizado esta variante técnica del repujado, en la que se emplea resina.

El profesor Tarradell en su ponencia, anteriormente citada los cataloga como: "pendientes o colgantes de oro en forma de paloma. Dos piezas similares, que hacen juego. Ejecutadas en plancha de oro, con filigrana de tradición helenística. Es la única joya encontrada en el Cerro de San Lorenzo con personalidad y carácter artístico".

Como bien dice el profesor Tarradell son similares, no exactamente iguales, las cabezas, los picos y los ojos son distintos y también el gancho que atravesaba la oreja es diferente en ambos pendientes. El hecho de que sean diferentes hace todavía más interesante y lograda la labor "artesanal" del artifice joyero que los realizo.

Siguiendo con la técnica, también se ha utilizado la "Filigrana" en estos pendientes, esta técnica más compleja que la anterior consiste, como decía al principio, en una adición de hilos, en este caso de oro también, que formando dibujos muy diversos se van soldando a la pieza metálica. Este trabajo resulta sobrepuesto y en relieve y puede presentar variaciones más o menos complicadas según que el hilo sea de mayor o menor grosor, esté o no retorcido, etc. El hilo de oro que se ha soldado a nuestra joya es finisimo, de menos de $1 \mathrm{~mm}$. de espesor y forma como veremos unos bellos dibujos, está retorcido, o por lo menos asi lo parece, aunque en algunos trozos parece que esté rehundido una vez soldado a la plancha de oro. Las dos láminas de oro que forman el cuerpo de la paloma están delicadamente unidas por la parte superior e inferior, que se acusa por una fina línea, la cola se incrusta prácticamente en la parte trasera del cuerpo. De los dos pendientes hay uno, el más pequefio que está roto, tiene un pequeño agujero en la parte superior, pero el otro que está intacto es un prodigio de perfección, ya que la soldadura de las dos láminas del cuerpo es prácticamente invisible.

Antes de pasar a la descripción detallada de los pendientes diré que las argollas y el gancho son de hilo de oro también aunque mucho más grueso que 
el de la filigrana, tendrá de $1,5 \mathrm{~mm}$. $02 \mathrm{~mm}$.

La cabeza está adornada con un círculo de hilo de oro que representa el ojo del ave, desmesuradamente grande para la cabeza, en tomo al cuello tiene soldado un hojo de oro, realizado con técnica de filigrana, bajo este hilo, a modo de collar tiene una cenefa de círculos de hilo de oro hechos con la misma técnica anterior.

En el pecho tiene una especie de babero hecho igualmente con hilo de oro, con ćrculos o más bien gotas en la parte inferior. $Y$ las alas de la misma forma realizadas acaban en corazones de hilo de oro, muy perfectos, este adorno de corazones se completa con un tercero en la parte superior a la misma altura que los laterales. Por último la cola es una lámina de oro formando una cola abierta en tres partes, cada una de ellas, semejantes a pétalos de flor están rodeadas de un pequeño tabique de oro, de tal forma que aparecen realzadas, tiene un gran parecido con la técnica que se sigue en el cloissonné o tabicado, sólo que aquí no parece que estos "comartimentos" se rellenaran con pasta vítrea, ni con otro material. El borde de los tabiques está decorado con hendiduras semejando filigrana.

El adorno más interesante de los pendientes son estos tres corazones que cité un poco más arriba, en la doctrina tradicional el corazón es el verdadero asiento de la inteligencia siendo el cerebro sólo un instrumento de realización, por ella, el cerebro corresponde a la luna y el corazón al sol en el sistema analógico antiguo. El corazón es la imagen del sol en el hombre, como el oro es la imagen del sol en la tierra.

Esto nos llevaría al material utilizado y su simbologia, el oro es la imagen de la luz solar y por consiguiente de la inteligencia divina; consecuentemente el oro simboliza todo lo superior, la glorificación, todo lo que es de oro o se hace de oro pretende transmitir a su utilidad o función esa cualidad superior. El oro constituye también el elemento esencial del simbolismo del tesoro escondido 0 dificil de encontrar, imagen de los bienes espirituales y de la iluminación suprema.

Segín la opinión de expertos el oro, único material de la joya estudiada, es muy puro, de 24 kilates. Pasare ahora a las medidas y al peso. Las medidas del pendiente mejor conservado son las siguientes:

$-25,50 \mathrm{~mm}$. de largo del pico a la cola.

$-8 \mathrm{~mm}$. de ancho en el cuerpo.

$-8,15 \mathrm{~mm}$. de ancho en la cola.

$-16 \mathrm{~mm}$. de alto desde la cabeza a la base.

El pendiente peor conservado es un poco más pequefio:

$-24 \mathrm{~mm}$. de largo del pico a la cola.

-9 $\mathrm{mm}$. de ancho en el cuerpo (quizá porque se ha abollado por la parte superior hace que sea más ancho en la parte baja).

$-8 \mathrm{~mm}$. de ancho en la cola.

$-14 \mathrm{~mm}$. de alto desde la cabeza a la base. 
El peso de los pendientes originales no me ha sido posible comprobarlo ya que he tenido dificultades para ello, pero basándome en el peso de las copias (que son de oro macizas) los originales no deben superar los 5 o 5,50 gramos cada uno.

\section{Clasificación de la joya y localización}

Estos pendientes creo que habria que clasificarlos como una joya de adomo femenino con un claro sentido mágico-religioso, en tomo a la simbologfa de la Diosa Madre Tanit. Existen unos zarcillos procedentes del Tesoro de La Aliseda, hoy en el Museo Arqueologico de Madrid, con una cronología del siglo VII a. C., se trata de unos pendientes de sanguijuela con flores de loto y palmitas como elementos decorativos fundamentales, pero que incluyen también unas pequeñas figuras de pájaros posiblemente aves de rapina, quizás águilas o halcones que colocados de perfil y afrontados aparecen a ambos lados de las palmitas. Estos pájaros tienen decoración a base de filigrana, como el resto del pendiente, con una técnica mucho más perfecta que la de nuestros pendientes, pero nos vale una posible comparación.

Parece ser que este "tesoro" que se encontró en una ciudad del interior de la Península hay que considerarlo menos como un "puro" producto del arte púnico que como el resultado de la influencia púnica ejercida sobre una producción local; en el caso de nuestros pendientes podra ser la hipotesis contraria: su calidad podría hacernos pensar que se trata de un producto de importación. Es algo atrevido hacer hipótesis al respecto, entre otras cosas porque carecemos de otras joyas parecidas o distintas que pudieran haber aparecido en esta misma necropolis del Cerro de San Lorenzo, posiblemente existieron, yo personalmente asi lo creo, pero las excavaciones "arqueológicas" que allí se realizaron dejaban mucho que desear, no eran rigurosamente cientificas y por lo tanto estas otras joyas pasarian a manos de algún particular, con lo que nos cierra el camino para realizar un estudio más completo de esas joyas y con ello tener una base mayor para determinar si realmente fueron obra de un artesano local o bien como decía antes un producto de importación... desgraciadamente siempre nos quedará esa incognita.

El Profesor Tarradell en la misma ponencia citada anteriormente nos dice que si bien es cierto que la colección del Museo de Melilla no representa la totalidad de lo exhumado en el cerro de San Lorenzo, si la parte esencial. Debido a la forma en que marcharon las cosas antes de la intervención de Fernández de Castro, algunas piezas, cuya cantidad e importancia no es posible evaluar, se dispersaron entre coleccionistas, aficionados y museos, de tal forma que es imposible seguirles la pista. Entre los objetos de esta serie que sí se ha podido localizar se encuentra un jarrito que se conserva en el Museo de Bilbao.

Más grave que la falta de materiales hallados esporádicamente en la primera época es el hecho de que no se guardaran los ajuares de cada sepultura por 
separado, así hoy (y mucho más ahora después de 35 años) se ignora en absoluto cómo se agrupaban los objetos con los consiguientes problemas insolubles de paralelismo entre unos tipos y otros y posibles evoluciones de cada uno.

El descubridor de nuestras joyas, Fernández de Castro, en su libro Melilla Prehispánica, en la página 231, nos dice al respecto del enterramiento femenino donde se encontraron los pendientes: "Los dichos efectos, al igual que todo lo hallado en la necrópolis, están depositados en el Ayuntamiento de Melilla, en espera de que termine la construcción del Palacio Municipal, donde se han habilitado locales para museo y biblioteca, lugar en que será instalado decorosamente, en su día, el Museo Arqueologico de Melilla"

El deseo de Fernández de Castro se cumplio, aunque no se instalo el Museo en el actual Ayuntamiento, sino en el recinto de Melilla la Vieja, y en el llamado Baluarte de la Concepción, lugar muy bello por sus vistas panorámicas al mar pero que, desgraciadamente, carecía de las mínimas medidas de seguridad, como se ha comprobado en más de una ocasión.

El Museo Municipal de Melilla alberga en sus vitrinas la totalidad (?) de lo encontrado en el Cerro de San Lorenzo y entre ellos estaban nuestros pendientes y digo estaban porque lo que habra era una copia de los mismos. La historia es la siguiente:

En 1953 con la ayuda de la Alta Comisarfa de Espana en Marruecos se procedió a restaurar el llamado Baluarte de la Concepción dentro del recinto de Melilla la Vieja, la parte exterior de la fortaleza, que hasta muy poco antes sirvio de polvorín, se le encomendo a ingenieros militares al mando del Comandante Santiago Norefía de la Cámara. El interior, en cambio, se restauró según el proyecto del arquitecto municipal Guillermo García Pascual ya que fue el Ayuntamiento quien se hizo cargo de la obra.

Y gracias a la iniciativa del Cronista Oficial de la Ciudad, Francisco Mir Berlanga, que fue su director durante muchos afios, el 11 de septiembre de 1953 fue inaugurado oficialmente quedando abierto al público, era alcalde de la ciudad Gabriel de Benito y Angulo. Este pequeño, pero interesante Museo tenfa una Sección Arqueologica bastante importante, por el número de piezas allf expuestas.

Precisamente dentro de esta Sección en el armario número 3 en la tabla segunda se encontraban nuestros pendientes, cito textualmente lo que Francisco Mir nos dice de ellos en su libro "Guia de Melilla la Vieja y su Museo": "Pendientes de oro en forma de paloma de bellísima y delicada factura. Se encontraron junto a otros pequeños adomos del mismo metal que también se exhiben, en una de las sepulturas de la necrópolis del cerro de San Lorenzo. En la misma tabla hay collares de ágata y de cuentas vidriadas y policromadas y un cráneo humano encontrado en el mismo yacimiento que posiblemente pudo pertenecer a la dama que los uso en vida".

El propio director del Museo, Francisco Mir, fue quien, a causa de las pocas medidas de seguridad del Museo, encargó a un joyero melillense, José Caparrós 
Mayo, una copia exacta de los pendientes en el affo 1980. Efectivamente unos años más tarde concretamente en 1986 robaron las copias de los pendientes y los aretes de oro del pelo originales, pues de éstos no tuvieron la precaución de hacerles copias. Los pendientes originales se llevaron en primer término a una caja fuerte del Ayuntamiento, pero más tarde se llevaron a una caja fuerte del Banco de Bilbao de la ciudad, donde están actualmente, a salvo para nuestra satisfacción. Por su parte las copias nuevas de los pendientes se ofrecen en las vitrinas del Museo Municipal de Melilla, en su nueva sede de la tradicional "Casa del Reloj", restaurada expresamente para albergar el Museo, en 1990. 